\title{
Network on Chip Optimization Based on Surrogate Model Assisted Evolutionary Algorithms
}

Wu, M., Karkar, A., Liu, B., Yakovlev, A., Gielen, G. and Grout, V.

This is a paper presented at the IEEE World Congress on Computational Intelligence, 6-11 July 2014, Beijing.

The full text of this paper is not available in this Repository. The definitive version is available at: $\underline{\text { http://ieeexplore.ieee.org/xpls/abs all.jsp?arnumber=6900559\&tag=1 }}$

(C) 2014 IEEE. Personal use of this material is permitted. Permission from IEEE must be obtained for all other uses, in any current or future media, including reprinting/republishing this material for advertising or promotional purposes, creating new collective works, for resale or redistribution to servers or lists, or reuse of any copyrighted component of this work in other works.

\section{Recommended citation:}

Wu, M., Karkar, A., Liu, B., Yakovlev, A., Gielen, G. and Grout, V. (2014), "Network on Chip Optimization Based on Surrogate Model Assisted Evolutionary Algorithms", in Proceedings of IEEE World Congress on Computational Intelligence, 6-11 July 2014, Beijing, pp. 3266-3271. doi: 10.1109/CEC.2014.6900559 